
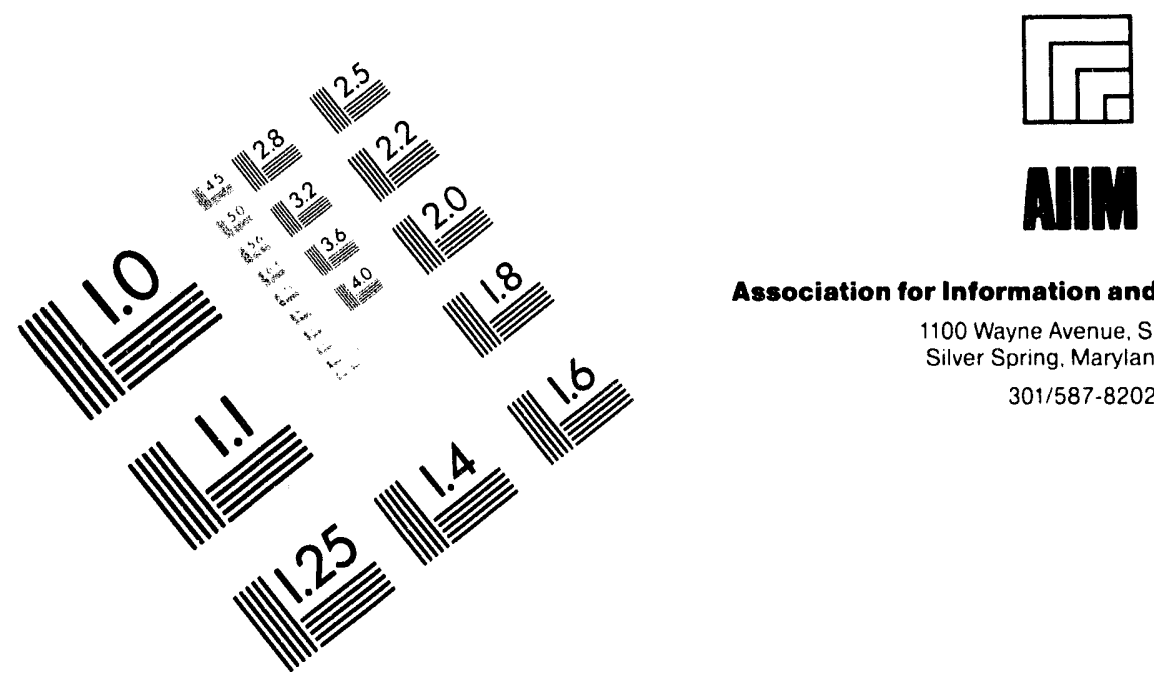

Association for Information and Image Management

1100 Wayne Avenue. Suite 1100

Silver Spring. Maryland 20910 301/587-8202

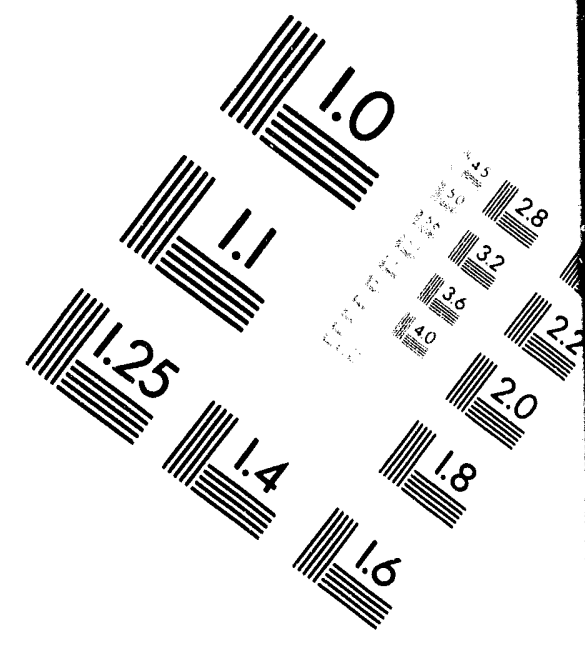

\title{
Centimeter
}

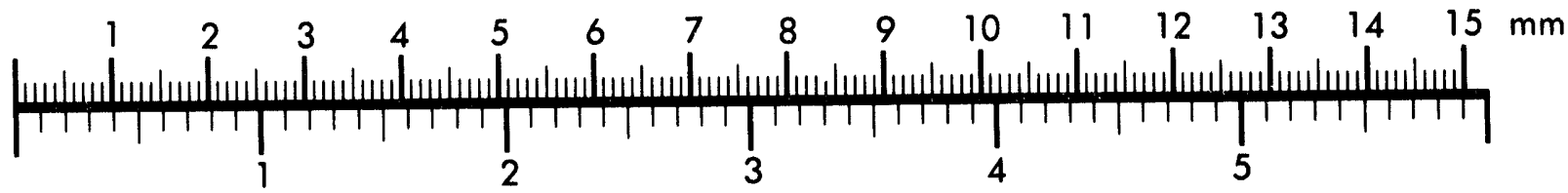

Inches
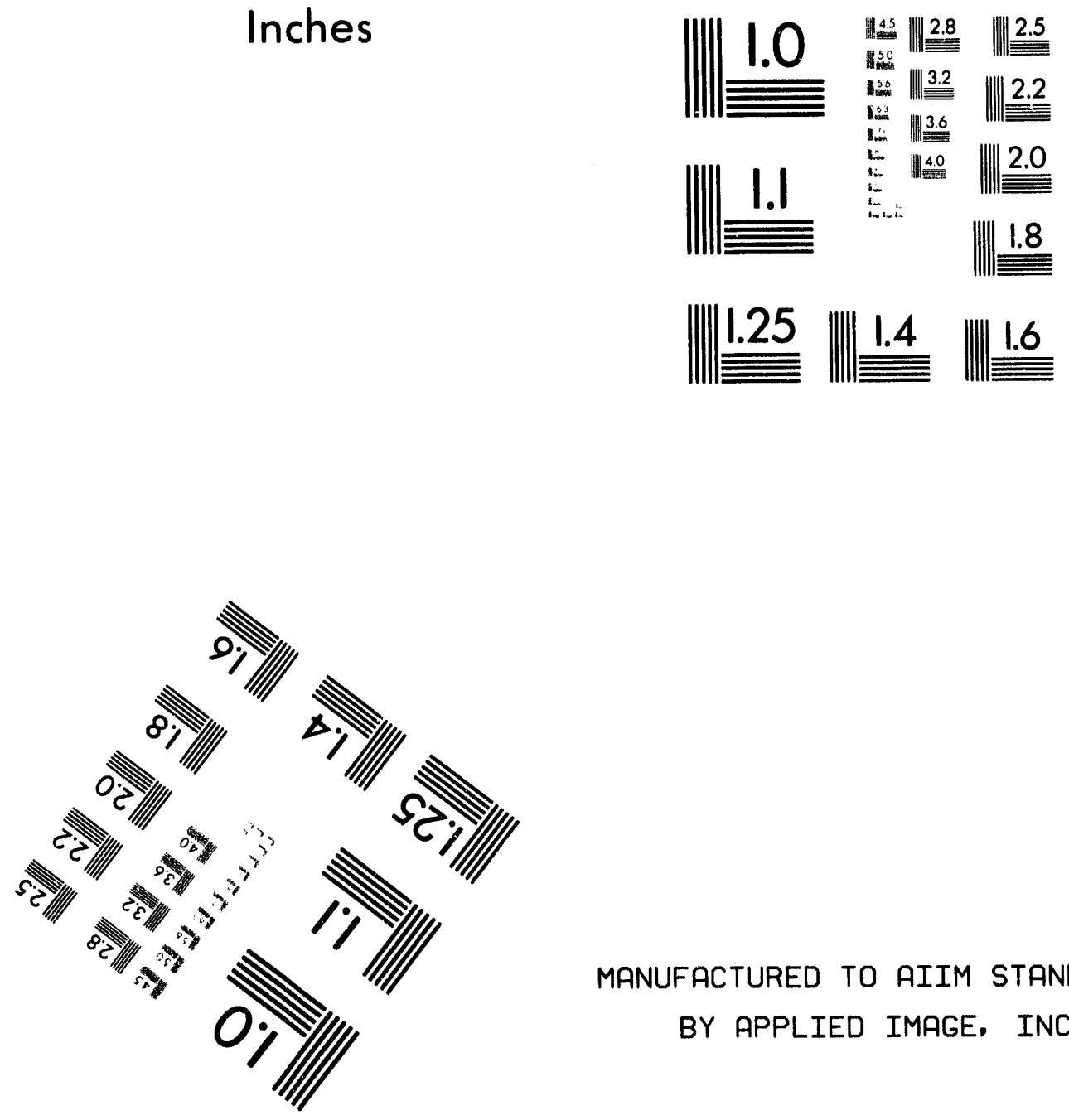

MANUFACTURED TO AIIM STANDARDS

BY APPLIED IMAGE, INC.

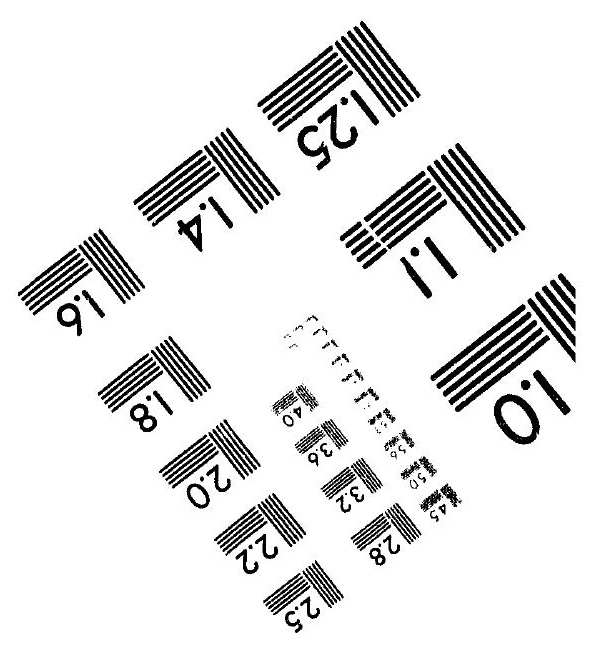



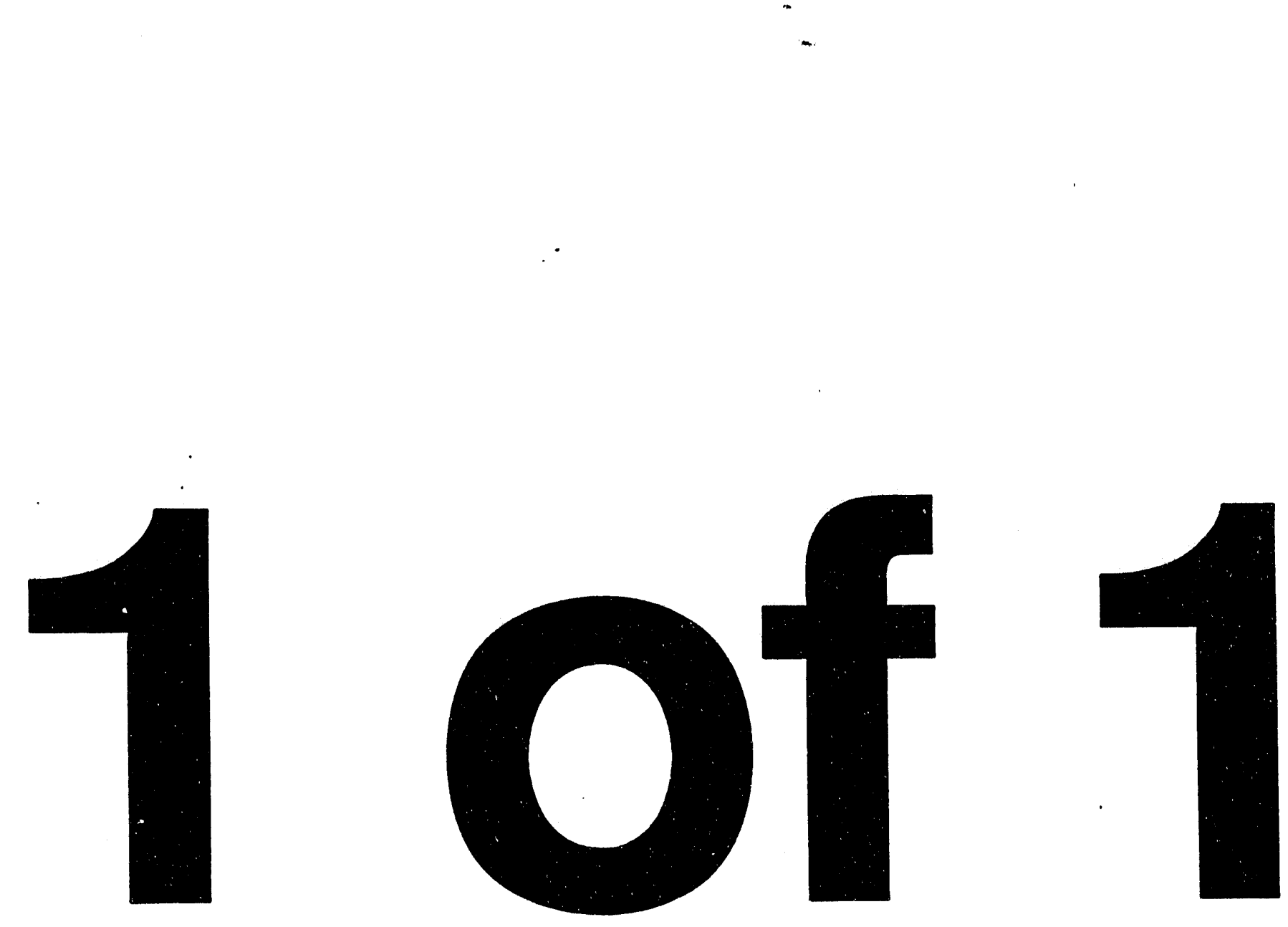


\section{PROJECT TECHNICAL PROGRESS REPORT}

\section{MICROBIAL COMMUNITIES IN SUBSURFACE ENVIRONMENTS: DIVERSITY, ORIGIN, AND EVOLUTION}

US Department of Energy Contract No. DE-FG02-90ER60989 $(9 / 1 / 93-8 / 31 / 96)$

to Rensselaer Polytechnic Institute (Sandra A. Nierzwicki-Bauer)

May 2, 1994

\section{DISCLAIMER}

This report was prepared as an account of work sponsored by an agency of the United States Government. Neither the United States Government nor any agency thereof, nor any of their employees, makes any warranty, express or implied, or assumes any legal liability or responsibility for the accuracy, completeness, or usefulness of any information, apparatus, product, or process disclosed, or represents that its use would not infringe privately owned rights. Reference herein to any specific commercial product, process, or service by trade name, trademark, manufacturer, or otherwise does not necessarily constitute or imply its endorsement, recommendation, or favoring by the United States Government or any agency thereof. The views and opinions of authors expressed herein do not necessarily state or reflect those of the United States Government or any agency thereof. 


\section{PROJECT DESCRIPTION}

This report summarizes the progress made in our laboratory from $9 / 1 / 93$ - present, towards completion of the experimental plan for DOE grant project entitled "Microbial Communities in Subsurface Environments: Diversity, Origin, and Evolution" (DOE Contract No. DE.FG02-90ER60989).

As participants in the subsurface science program we are assessing the influence of environmental conditions on the distribution and evolution of subsurface microorganisms employing molecular techniques. Our approach utilizes $16 \mathrm{~S}$ rRNA targeted oligonucleotide probes, polymerase chain reaction (PCR) amplification of gene sequences, and sequencing techniques.

DNA has been extracted from natural microbial communities present in subsurface sediments. Specifically, lacustrine subsurface sediments obtained from the Hanford site (GEMHEX sequence) have been used. Following PCR amplification, 16S rRNA amplification products will be subcloned, screened, sequenced and analyzed. Of particular interest is the comparison of surface versus subsurface microbial communities and whether it is possible to identify unculturable organisms that are the survivors or progeny of microorganisms associated with the original geological deposits.

Isolates obtained from surface and subsurface sediments at the GEMHEX borehole are being phylogenetically classified using 16S rRNA targeted probes. Since only 30 original isolates were obtained from this borehole we have also been identifying isolates from the GEMHEX sediment storage experiments. Continued progress towards identifying target sequences for selected microbial types and groups is being made by analysis of rRNA sequence data for subsurface microorganisms and other microorganisms in the rRNA databases. Hybridization probes for these target sequences are being produced and used to classify isolated strains of subsurface microbes into "focus clades" useful for testing origins hypotheses.

Finally, we are conducting a survey of subsurface pseudomonad strains for the presence of Group I self-splicing introns, which may be ancient features of gene structure. To date, we have tentatively identified 15 subsurface pseudomonad strains which contain Group I self-splicing introns. 
II. PROPOSED MAJOR RESEARCH ACTIVITIES (1993 - 1995)

\section{Year 1:}

- Phylogenetic classification of surface and subsurface GEMHEX isolates (Original and storage isolates).

- Extraction of DNA from lacustrine GEMHEX samples and selection of clones for subsequent analysis of $16 \mathrm{~S} \mathrm{rRNA}$ sequences.

- Survey of subsurface isolates for the possession of Group I self-splicing introns.

- Continue 16S rRNA-targeted probe design.

Progress on these objectives are detailed in the Project Output Section of this report.

Year 2:

- Begin sequence analysis of $16 \mathrm{~S}$ rRNA clones from the GEMHEX samples.

- Initiate sequencing and analysis of Group I introns.

- Continue probe design.

Year 3:

- Complete analysis of 16S rRNA clones from GEMHEX samples.

- Continue analysis of Group I self-splicing introns in subsurface microorganisms.

- Continue probe design as needed.

Note: Additional proposed research activities which could be carried out in conjunction with other investigators and field programs for testing origins and transport hypotheses are described in Section IV (Preliminary Results For Future Work). 
III. PROJECT OUTPUT: Major accomplishments (9/1/93 - 4/30/93)

\section{A. EXTRACTION AND PURIFICATION OF DNA FROM SUBSURFACE SEDIMENTS}

A primary research goal of our laboratory is the phylogenetic analysis of unculturable microorganisms from GEMHEX sediment samples. To accomplish this goal it has been necessary to develop methodology to extract high quality DNA from GEMHEX sediment samples. This has been required because existing DNA extraction protocols have been unsuccessful with GEMHEX lacustrine sediments (Vescio and Nierzwicki-Bauer, submitted).

Our specific objectives have been:

I. Develop methods of DNA extraction and purification from GEMHEX sediments.

II. Extract and purify total community DNA from several of the GEMHEX lacustrine sediments for PCR amplification and sequence analysis.

I. DNA extraction. A DNA extraction procedure to recover high quality DNA from microbial communities in lacustrine type sediments has been developed. This method employs direct lysis of cells in an agarose-sediment mixture, electroelution of community DNA, followed by ammonium acetate precipitation for further purification. The extracted community DNA was found to be suitable for PCR amplification with $16 \mathrm{~S}$ rRNA gene specific primers when $\mathrm{T} 4$ gene 32 protein was included in amplification reactions.

We have submitted a manuscript detailing this procedure to the Journal of Microbiological Methods. Vescio, P.A. and S.A. Nierzwicki-Bauer. Extraction and purification of PCR amplifiable DNA from lacustrine subsurface sediments.

II. Analysis of total DNA from subsurface sediments. During the past six months we have utilized our DNA extraction protocol to obtain community DNA from three lacustrine sediments (G3, G5, and G13) that had been stored at $-20^{\circ} \mathrm{C}$ since their acquisition. Using universal PCR oligonucleotide PCR primers (previously developed), we have successfully amplified the $16 \mathrm{~S}$ rRNA genes from this community DNA. These PCR amplifications yield 1100 bp products which contain sufficient sequence information for accurate phylogenetic analyses. Currently we are in the process of subcloning these PCR products into sequencing vectors for sequence analysis. 
Summary.

During the past six months we have developed technology to successfully extract DNA from subsurface lacustrine sediments which is suitable for molecular analysis. We have submitted for publication a manuscript describing this protocol. During the next grant period we will begin generating $16 \mathrm{~S}$ rRNA sequence data from these DNA samples.

\section{B. EFFECTS OF STORAGE ON GEMHEX SAMPLES}

Since initiation of the grant period (9/93 to 4/94) one area of investigation in our laboratory has involved the determination of storage effects on GEMHEX sediment cores.

Specifically, two hypothesizes are being evaluated:

I. Storage of core material in an intact form (i.e. not homogenized) permits a more representative analysis of deep subsurface sediment microbial communities. Storage of fixed samples does not significantly alter the total cell numbers observed.

II. Diversity and community structure of culturable organisms from the GEMHEX sediments are effected by storage and/or the addition of nutrients or moisture amendments.

I. Storage of intact versus homogenized cores. To test the first hypothesis, we received formalin fixed paleosol sediments from the GEMHEX interval (617 feet) which were stored either as intact (G20) or homogenized (YB32) core samples. Storage of core material was carried out at PNL for up to 21 weeks after collection and prior to fixation. In some cases replicates of the samples were available. Total cell counts and total metabolically active cell counts were obtained using coumarin staining and hybridization with 16S targeted rRNA universal probes labeled with rhodamine, respectively. Protocols previously developed in this laboratory were used for these analyses, and the results are shown in Table 1.

Statistical comparisons of replicate samples indicated no differences within samples during the storage period for either the $G 20(p<0.5 ; \mathrm{df}=4)$ or $\mathrm{YB} 02-32(\mathrm{p}<0.4$; $\mathrm{df}=4$ ) samples. However, the variability of the active cell counts in both samples was high. Since there were no differences that could be attributed to storage of the samples the total cell count values for each sample were pooled and a comparison between treatments (intact vs. homogenized) was made. A significant difference in total counts between the samples was observed $(p<0.05 ; d f=12)$, suggesting that higher total cell 
counts occur in the homogenized sample. However, no significant differences in the number of metabolically active cells between either sample was detected $(p<.90 ; \mathrm{df}=12)$.

Table 1. In situ cell counts of GEMHEX samples stored intact or homogenized

\begin{tabular}{|c|c|c|}
\hline $\begin{array}{l}\text { Storage Time } \\
\text { (Weeks) }\end{array}$ & $\begin{array}{l}\text { Total cells } \\
\text { per gram sediment }\end{array}$ & $\begin{array}{l}\text { Active cells } \\
\text { per gram sediment }\end{array}$ \\
\hline \multicolumn{3}{|l|}{ G20 Sample (Intact) } \\
\hline 1 & $4.1(0.5) \times 10^{7}$ & $1.88(1.0) \times 10^{6}$ \\
\hline 3 & $4.0 \times 10^{7}$ & $6.8 \times 10^{5}$ \\
\hline 10 & $2.5(3.2) \times 10^{?}$ & $1.9(3.2) \times 10^{7}$ \\
\hline 21 & $5.7 \times 10^{7}$ & $1.2 \times 10^{6}$ \\
\hline AVG & $3.7(2.1) \times 10^{7}$ & $7.9(18.6) \times 10^{6}$ \\
\hline \multicolumn{3}{|c|}{ YB02-32 (Homogenized) ${ }^{B}$} \\
\hline 3 & $1.2(7.9) \times 10^{8}$ & $6.5(7.6) \times 10^{6}$ \\
\hline 10 & $5.9(1.1) \times 10^{7}$ & $2.0(1.3) \times 10^{6}$ \\
\hline AVG & $8.9(6.0) \times 10^{7}$ & $4.6(5.2) \times 10^{6}$ \\
\hline
\end{tabular}

\footnotetext{
${ }^{A}$ Numbers in parenthesis indicate standard deviations $(n=3)$ for replicated samples.

Values without standard deviations indicate cell counts from single samples.

${ }^{B}$ YB02-03 1 and 21 week storage samples were not available.
}

Storage of fixed GEMHEX sediments. As a corollary to these investigations we have also determined the effect of storage on microor ${ }_{b}$ anisms within formalin fixed GEMHEX sediments. These investigations were conducted to determine how long fixed samples could be stored prior to analysis using 16S rRNA targeted probes without compromising data quality.

Total cell counts in three replicate GEMHEX paleosol sediment samples from a depth of $617 \mathrm{ft}(\mathrm{G} 20)$ were determined after weeks or months of storage in fixative. One sample was fixed on site (9/92), another was sent to our laboratory (9/92) and fixed and counted upon arrival, and a third was fixed in our lab in $9 / 92$ but not counted for 6 months (3/93). No significant differences were observed between the three samples indicating that fixed sediment samples can be stored for at least 6 months prior to analysis. 
II. Phylogenetic analysis of microorganisms cultured from GEMHEX storage samples. To test the second hypothesis, we have begun to rapidly identify isolates obtained from the GEMHEX and GEMHEX storage sediments using 11 group specific $16 \mathrm{~S}$ rRNA probes. This work is being accomplished using the in situ hybridization method which we have previously developed. These studies are being conducted in collaboration with D. Balkwill (FSU) and F. Brockman (PNL).

Since $2 / 94$ we have been receiving storage isolates from D. Balkwill's laboratory. Each strain is uniquely identified by an identifier number (ZAT[strain number]). However, we are blind testing these strains (i.e. we do not know from which experiment any particular isolate originated). To date we have received a total of 293 strains. Analysis of these strains involves four steps. First, the strains are cultured in the laboratory and glycerol stocks are made. Slides (15) of each culture are prepared for in situ hybridization analysis and stored until use. These slides can be stored for up to one year under desiccated conditions. Each culture (on a slide) is initially tested using universal 16S rRNA targeted probes tagged with the fluorescent molecule TRITC (rhodamine). If a hybridization signal is not detected for a specific culture, the strain is re-grown, and new slides are prepared. Following verification of cell viability (based on $16 \mathrm{~S}$ rRNA content), each strain is hybridized with each of 11 16S rRNA targeted oligonucleotide probes which have been designed to recognize phylogenetically distinct bacterial groups. The 11 probes which are being utilized include the following: FLAVO (Elavobacterium); PPT (Pseudomonas testosteroni); PPC (Pseudomonas cepacia); PSM $\mathrm{G}$ (general pseudomonad probe, includes fluorescent pseudomonad strains); ALPHA (the alpha proteobacteria including Agrobacterium); BETA (the beta proteobacteria including members of the genera Alcaligenes and Chromobacterium); combined PAC, PPA3 and GAMMA (the gamma proteobacteria); ENT (enteric subgroup of the gamma proteobacteria); PAG (Arthrobacter globiformis); HI G+C (Fumicuta including Arthrobacter and the Bifidobacteria); and LO G+C (Bacillus). The specificity of these probes have been demonstrated previously.

To date we have prepared slides and glycerol stocks of 137 of the 293 strains received. 63 strains have been examined with the FLAVO probe, 10 with the PPT probe, 9 with the GAMMA probe, 69 with the BETA probe, 15 with the PPC probe and 13 with the $\mathrm{HI} \mathrm{G}+\mathrm{C}$ probe. Five strains have been positively identified, 3 as belonging to the $\mathrm{HI}$ $\mathrm{G}+\mathrm{C}$ group and 2 to the Flavobacterium. We intend to complete screening of all strains by mid-July, 1994. Table 2 summarizes our progress of these analyses. 
Table 2. Progress (as of 4/22/94) classifying GEMHEX isolates.

\begin{tabular}{lcc}
\hline Analysis Step & Number Completed & $\%$ of Total \\
\hline Received & 293 & 100 \\
Slides Prepared & 137 & 46.75 \\
Tested for rRNA content & 91 & 31.0 \\
Identified & 5 & 1.7 \\
\hline
\end{tabular}

III. Probe design. During this period we have also continued development of our computer protocols for probe design. This work has included software updates as well as experimental testing of new probes.

Experimental studies have focused on evaluating computer predictions for probe design. Computer predictions are derived solely from primary structure (i.e. sequence) considerations and have not accounted for possible effects of secondary structure of rRNA or ribosomal protein interaction. To date, our data has indicated that both secondary structure as well as the primary structure of the probe (oligonucleotide sequence) influence the efficacy of a particular oligonucleotide sequence for use as a probe for the in situ hybridization assay. This knowledge improves our ability to design oligonucleotide probes. In addition, this work has generated new universal probe sequences for experimental use.

\section{SURVEY FOR PRESENCE OF GROUP I SELF-SPLICING INTRONS IN DEEP SUBSURFACE PSEUDOMONAD STRAINS}

Another objective addressed during this grant period has been the screening of subsurface pseudomonad isolates for the presence of Group I self-splicing introns. Because Group I introns are believed to be ancient features of gene structure, the presence of these motifs in subsurface microorganisms may provide evidence for the ancient origins of subsurface microbial populations. Furthermore, the discovery and genetic analysis of Group I introns from these strains will provide insight into the evolution of prokaryotic as well as eukaryotic genomes. 
Specific objectives addressed:

I. Development of probe/primers to detect Group I self-splicing introns in microbial isolates from subsurface sediments.

II. Determination if subsurface pseudomonad strains from the P24 borehole (Savannah River Site) contain Group I self-splicing introns.

I. Probe development. Based on conserved DNA sequences from the seven known prokaryotic Group I self-splicing introns, three oligonucleotide probes were designed ( $\mathrm{P}$ 2, $\mathrm{Q}$, and S) to enable detection of Group I introns in deep subsurface bacteria. These probes were evaluated against positive and negative controls to determine their specificity. Probe $\mathrm{Q}$ was determined to be the most specific, although both $\mathrm{P} 2$ and $\mathrm{S}$ may also have utility as secondary screening tools.

II. Survey of isolates. Probe $\mathrm{Q}$ was used to screen fifty subsurface Pseudomonad strains for the presence of Group I self-splicing introns. These strains were originally isolated from the P24 borehole at the Savannah River Site. Fifteen of the fifty isolates tested possessed sequence homology to probe $Q$ and thus, are likely to contain Group I selfsplicing introns.

The occurrence of Pseudomonads containing introns within the borehole was clustered at two depths. Ten intron positive isolates originated from depths between 45 and 118 meters, and another cluster of five intron positive isolates originated from depths of 244 to 265 meters.

III. Genetic analysis of Group Lintrons from subsurface pseudomonad strains. Restriction digestion and Southern blot analysis of genomic DNA from putative intron containing strains has been initiated. From the eight strains examined to date, four unique restriction fragments (containing homology to the intron probes) have been identified. This suggests a high degree of diversity among introns from these different strains. These fragments will be cloned and sequenced.

To further isolate introns from psuedomonad strains and to confirm the presence of introns, we have also been using the oligonucleotide probes as Polymerase Chain Reaction (PCR) primers. This technique allows us to amplify putative introns from total genomic DNA. However, because the PCR assay is dependent on homology of two primers, its usefulness is limited to sequences with a high degree of homology to known Group I introns of surface organisms. Nevertheless, using this approach we have been able to amplify a PCR product of the expected size from one psuedomonad strain (B141). 


\section{Summary.}

In summary, methods have been developed for the detection of Group I introns in subsurface bacteria. Results of preliminary screening of 50 subsurface psuedomonad strains indicate that $30 \%$ of the isolates may contain group I introns. The presence of Group I introns in subsurface strains may suggest an ancient origins. PCR amplification products and restriction fragments homologous to intron probes are available for further analysis, including sequencing and confirmation by detection of intron self-splicing activity.

\section{PRELIMINARY RESULTS FOR FUTURE WORK}

In addition to the progress we have made related to our specific grant objectives, during the past six months we have conducted several exploratory projects pertaining to the DOE Deep Subsurface ORIGINS and TRANSPORT programs.

A. Microbiological analysis of trial sediment samples from the Cerro Negre site. As agreed upon at the Origins meeting (11/94), we were sent trial samples collected from near the proposed ORIGINS drilling site, to determine if they contained bacterial cells and if our current methods were suitable for analysis of these samples. Five sets of sediment samples from the Gavilon and Cubero sites were sent to us and were examined for the presence of both total and metabolically active cells.

Cells were observed in all samples. Total counts ranged from 2.89 to $7.32 \times 10^{6}$ cells per gram/sediment, while active cell counts ranged from $5.1 \times 10^{5}$ to $2.21 \times 10^{6}$ cells per gram/sediment (Table 3 ). In general, the samples were relatively easy to analyze using previously developed techniques, with background fluorescence levels being low.

Table 3. Total and active cell counts from DOE origins site trial samples.

\begin{tabular}{lllc}
\hline Sample & $\begin{array}{l}\text { Total cell counts } \\
(\mathrm{gm} / \text { sediment })\end{array}$ & $\begin{array}{l}\text { Active cell counts } \\
(\mathrm{gm} / \text { sediment })\end{array}$ & $\begin{array}{c}\% \text { Active } \\
\text { cells }\end{array}$ \\
\hline Gavilon \#1 & $7.32 \times 10^{6}$ & $2.21 \times 10^{6}$ & 30.2 \\
Gavilon \#2 & $5.61 \times 10^{6}$ & $1.02 \times 10^{6}$ & 18.2 \\
Gavilon \#3 & $5.61 \times 10^{6}$ & $1.70 \times 10^{6}$ & 30.3 \\
Gavilon \#4 & $2.89 \times 10^{6}$ & $5.10 \times 10^{5}$ & 17.6 \\
Cubero \#1 & $3.91 \times 10^{6}$ & $2.04 \times 10^{6}$ & 52.2 \\
\hline
\end{tabular}


These preliminary results indicate that our current methodologies can be used to study microbial community structure of sediment from the Cerro Negro site.

B. Modification of in situ hybridization assay for analysis of TRANSPORT samples. In anticipation of receiving TRANSPORT sediment samples, we have begun to adapt our in situ hybridization protocol for use with a flotation technique useful for the examination of soil and sediment microorganisms which has previously been developed in Balkwill's laboratory (Bone and Balkwill, 1986). To this end, Dr. Nierzwicki-Bauer spent three days in Dr. Balkwill's laboratory learning the technique and formulating the modifications which will be required for use in conjunction with $16 \mathrm{~S} \mathrm{rRNA}$ targeted oligonucleotide probes. Currently, we are setting-up the modified floatation assay at Rensselaer and trouble-shooting the assay using archived sediment samples. During this time period, we have also started to design group specific 16S rRNA targeted probes for Streptomyces spp. This preliminary work should facilitate testing TRANSPORT hypotheses. This work will be done in collaboration with D. Balkwill (FSU) and Ellyn Murphy (PNL).

\section{Summary.}

In summary, we have or will shortly achieve all of the stated Year One objectives. Additionally, we have demonstrated the applicability of our molecular techniques to sediments of the type to be analyzed for new Origins field sampling and, if possible, look forward to the analysis of these samples. Although funding for these activities has not been specifically targeted, it is felt that if desired we could make significant contributions to these projects, based on our preliminary studies using molecular techniques. 

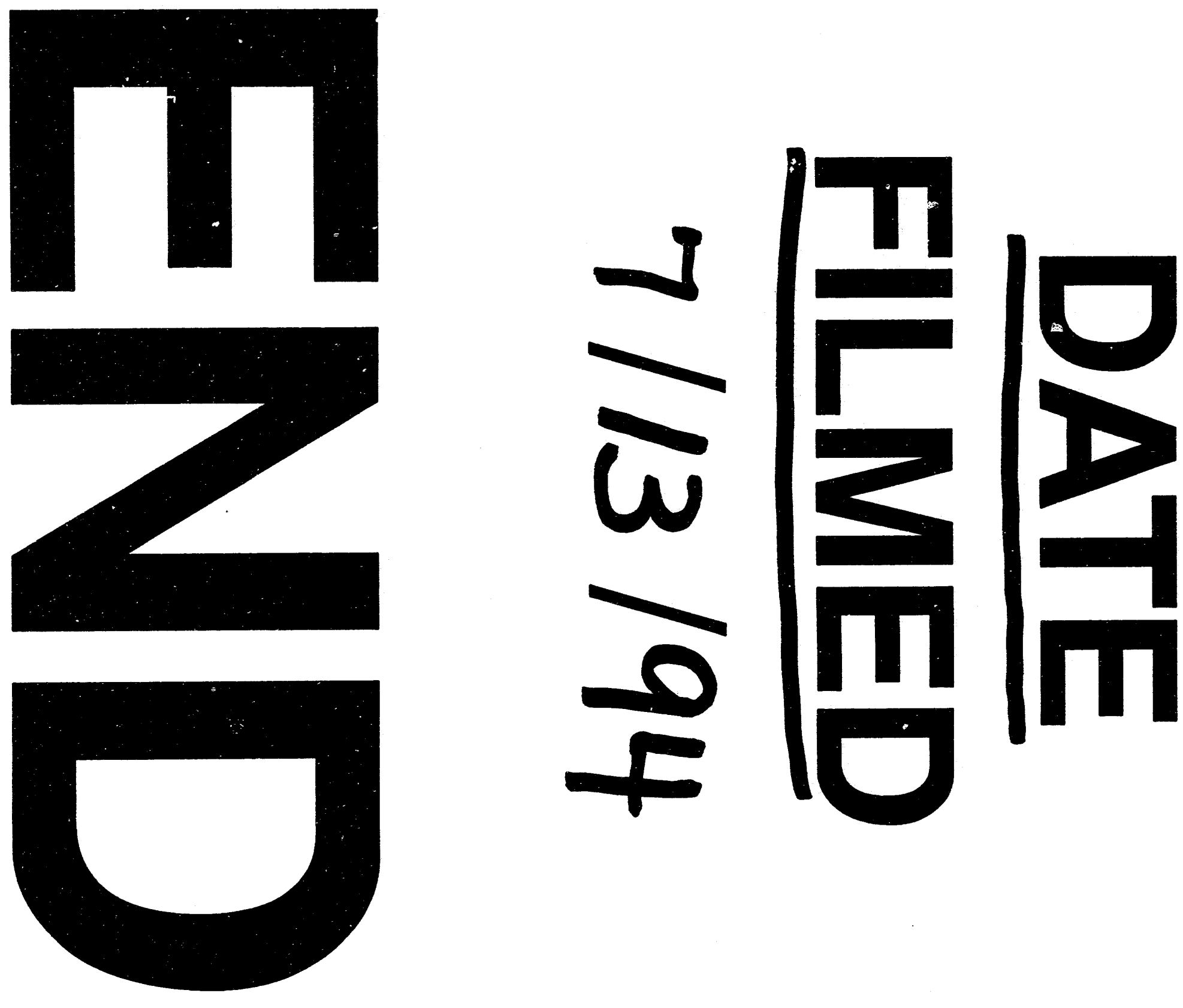
